\title{
Formulation and Evaluation of Chlortenoxicam Rectal Suppositories
}

\author{
B.Nage ndrababu ${ }^{* 1}$, P. Venkates wara Rao ${ }^{1}$, K. Ke erthi $^{1}$, L.Vine etha ${ }^{1}$, P. Priyanka ${ }^{1}$ \\ ${ }^{*}$ Department of Pharmacy, St. Mary's Group of Institutions Guntur, Chebrolu (V\&M), Guntur, Andhra \\ Pradesh, India.
}

*Corresponding Author: B. Nagendrababu, Department of Pharmacy, St. Mary's Group of Institutions Guntur, Chebrolu (V\&M), Guntur, Andhra Pradesh, India.

\begin{abstract}
The aim of the present study was to formulate chlortenoxicam into rectal suppositories as a new dosage form, to avoid its reported gastric irritation and to provide a rapid onset of action for children. Suppositories were prepared using fatty bases mixtures of poly (ethylene glycol), PEGs, with different molecular weights. The prepared suppositories were investigated for their weight variation, drug content, melting point, fracture point, disintegration time and in-vitro release pattern. The in vitro release study was performed USP type-I apparatus (basket type) using phosphate buffer pH7.4 as dissolution media. The suppositories prepared were within permissible range of all physical parameters, in-vitro drug release from water soluble bases like PEG was greater than that of oil soluble bases. Addition of HPMC in agar suppositories to control release. The result suggest that of PEG of low molecular weight with high molecular weight in different percentage of release. The sustained release suppository can be prepared by addition of HPMC in agarbased suppositories and by use of beeswax in cocoa butter as base.
\end{abstract}

Keywords: Lornoxicam, Rectal suppositories, agar, PEGs bases, HPMC Bees wax, In-vitro study

\section{INTRODUCTION}

Chlortenoxicam is considered one of the potent non-steroidal anti-inflammatory drugs, NSAIDs, with analgesic and anti-pyretic properties and is structurally related to piroxicam and tenoxicam; however, it is ten times more potent than both of them. Chlortenoxicam inhibits both cyclooxygenase iso enzymes cox-I and cox-II, hence the gastrointestinal adverse effects still an issue especially with oral administration . Because it is used as a potent postoperative analgesic, and the rapid onset of action is a desired attribute especially for infants and elderly patients. The drug is available in the Egyptian market in the forms of oral tablets and parenteral formulations only. At the same time, there was no data in the literature regarding Chlortenoxicam rectal formulation. Rectal route of NSAIDs is one of the alternative routes to avoid gastro-intestinal problems. In addition, absorption of the drugs from rectal mucosa directly into venous circulation may bring about faster action than that observed after oral administration and this is very important especially with drugs used to reduce post-operative pain. Recently, Chlortenoxicam was formulated in the form of rectal suppositories for treatment of patients suffering from post-operative pain and edema following maxillofacial operations. The aim of this work was to formulate LOR in a rectal dosage form, suppositories, to fulfill many aspects e.g., rapid onset of action, avoiding GIT problems, as well as enhancing patients compliance especially for elderly people and children. Different formulations were prepared using fatty and water soluble, PEG, bases and investigated for their weight variation, drug content, hardness, dis integration time, melting range, in-vitro release.

\section{Materials AND Methods}

Chlortenoxicam, PEG 4000,400 are collected from FDC Limited, Mumbai. Agar, Propyl paraben, Propylene Glycol, Cocoa butter, HPMC (E15) were collected from Fine chemical Industry, Mumbai.

\subsection{Preparation of Chlortenoxicam Suppositories}

Agar suppositories were prepared by molding method, dissolving methyl and propyl paraben in hot water and then drug along with other additives like propylene glycol, HPMC, was added and mixed well. Finally agar was incorporated at $75-80^{\circ} \mathrm{C}$ and mixed thoroughly. The molten mass was poured 
into previously calibrated by stainless steel mould of $1 \mathrm{gm}$ and allowed to set and kept in freeze for cooled for some time and removed it. The PEG suppositories were prepared by using fusion method by melting PEG $(400,4000)$ in different ratios and then drug was incorporated(7). Cocoa butter suppositories were prepared by melting cocoa butter and bees wax on water bath and then the drug was incorporated. The details of all formulations are tabulated in table 1 and 2. All the Prepared suppositories were packed in Aluminum foil kept in.

Table1: Formulation of Chlortenoxicam Rectal Suppositories

\begin{tabular}{|c|c|c|c|c|c|c|}
\hline Ingredients (\% w/w) & F1 & F2 & F3 & F4 & F5 & F6 \\
\hline Chlortenoxicam & 10 & 10 & 10 & 10 & 10 & 10 \\
\hline Agar & 5 & 5 & 5 & 5 & 5 & 5 \\
\hline Propylene glycol & 10 & 10 & 10 & 10 & 10 & 10 \\
\hline Methyl paraben & 0.04 & 0.04 & 0.04 & 0.04 & 0.04 & 0.04 \\
\hline Propyl paraben & 0.02 & 0.02 & 0.02 & 0.02 & 0.02 & 0.02 \\
\hline HPMC(E15) & - & 2 & 4 & - & - & - \\
\hline Water(qs) & - & - & - & - & - & - \\
\hline PEG4000 & - & - & 60 & 80 & - & - \\
\hline PEG 400 & 40 & 20 & 40 & 20 & - & - \\
\hline
\end{tabular}

\subsection{Calibration of Mould}

Before preparing the suppositories, the mould should be calibrated because the moulds may vary in their capacity. The base was melted alone and then filled into the mould and weighed after removing the suppositories; the mean weight was taken as true capacity of the mould. The procedure was repeated for different bases. The calibrated mould capacities ranged from 1.02 to $1.195 \mathrm{~g}$.

\subsection{Evaluation of Suppositories}

The prepared suppositories were evaluated for official and unofficial parameters.

\subsubsection{Weight Variation}

All the suppositories (made by the respective bases), were weighed and average weight was calculated. Then all the suppositories were individually weighed and the variation from the average was calculated. No suppositories should deviate from average weight by more than $5 \%$ except two which may deviate not more than $7.5 \%$.

\subsubsection{Hardness (Fracture Point)}

Hardness of the prepared suppositories was tested using Monsanto hardness tester model. The weight required for suppository to collapse was taken as measure of hardness of the suppository. Hardness test or fracture point test was carried to determine the tensile strength of the suppositories to access whether they will be able to withstand the hazards of packing and transporting.

\subsubsection{Disintegration Test}

The disintegration test was performed on six suppositories of each type using USP tablet disintegration (Electro lab, ED 2L) test apparatus. $160 \mathrm{ml}$ of distilled water was used as medium at $37^{\circ} \mathrm{C}$. Suppositories prepared with water soluble bases the time required for comple te disintegration and in case of oily bases, the time required for complete Disintegration of suppository was determined.

\subsubsection{Macro Melting Range Test}

For macro melting range test the formulation was filled to about $1 \mathrm{~cm}$ height in capillary tubes of 10 $\mathrm{cm}$ length and dipped in a beaker containing water. The temperature was raised slowly and the temperature at which the mass liquefies was recorded.

\subsubsection{Liquefaction Time \& Temperature}

For Liquefaction time and temperature was done using fabricated instrument. A big pipette was taken having a narrow opening on one side and broad opening on another side. The pipette was dipped in hot water maintained at $37^{\circ} \mathrm{C}$. So that narrow end faces toward hot water. The sample suppository was introduced from the top of the pipette through broad end and carefully pushed down its length until it 
reaches narrow end. A glass rod was then inserted so that it rests over the suppository. The temperature at which the glass rods just come down was noted that represents the liquefaction temperature. The time at which glass rod reaches to narrow end after complete melting of suppositories represents the liquefaction time.

\subsubsection{Drug Content}

For determination of drug content the suppositories were dissolved in $100 \mathrm{ml}$ phosphate buffer of $\mathrm{pH}$ 7.4 by stirring through magnetic stirrer slowly at $37^{\circ} \mathrm{C}$ for $1 \mathrm{hr}$. After the solution was filtered; and the filtrate was diluted suitably and absorbance was measured against blank at $371 \mathrm{~nm}$.

\subsubsection{Dissolution Test}

In vitro dissolution studies of Chlortenoxicam suppos itories were carried out in USP tablet dissolution test apparatus (Electro lab -TDT 08L) employing a rotating basket apparatus (Type I) at $100 \mathrm{rpm}$ and using $500 \mathrm{ml}$ of phosphate buffer $(\mathrm{pH} 7.4)$ at $37 \pm 0.5^{\circ} \mathrm{C}$ as dissolution medium. One suppository was used in each test. At predetermined time intervals $5 \mathrm{ml}$ sample were withdrawn by means of syringe fitted with a pre filter then filtered through watman filter paper. The volume withdrawn at each interval was replaced was replaced with same quantity of fresh dissolution medium and maintained at $37 \pm 0.5^{\circ} \mathrm{C}$. The sample were analyzed for drug release by measuring the absorbance at $371 \mathrm{~nm}$ using UV-visible spectrophotometer after suitable withdrawn sample cumulative percent of lornoxicam released was calculated and plotted against time. All the studies were run in triplicate $(n=3)$.

\section{RES ULTS AND DIS CUSSION}

Table2: Evaluation of Suppositories for Various Parameters

\begin{tabular}{|c|c|c|c|c|c|c|c|}
\hline Batches & Drug content & Weight variation & Hardness & $\begin{array}{c}\text { Disintegration time } \\
(\mathbf{m i n})\end{array}$ & $\begin{array}{c}\text { Macro } \\
\text { melting }\end{array}$ & $\begin{array}{c}\text { TIME } \\
(\mathbf{m i n})\end{array}$ & $\begin{array}{c}\text { Temp. } \\
(\text { oc) }\end{array}$ \\
\hline F1 & $95.44+0.036$ & $1.000+0.011$ & 1.5 & $>9$ & $54-56$ & $8-10$ & $52-54$ \\
\hline F2 & $95.44=0.025$ & $1.001+0.029$ & 1.5 & $>9$ & $54-56$ & $10-12$ & $54-56$ \\
\hline F3 & $95.90+0.025$ & $1.003+0.026$ & 2 & $>9$ & $56-58$ & $14-16$ & $56-58$ \\
\hline F4 & $96.81+0.035$ & $0.999+0.022$ & 1.5 & $>9$ & $56-58$ & $12-14$ & $52-54$ \\
\hline F5 & $96.58-0.045$ & $1.005-0.012$ & 2.0 & $>9$ & $56-58$ & $8-10$ & $52-54$ \\
\hline F6 & $96.36-0.060$ & $1.0077-0.026$ & 2.0 & $>9$ & $56-58$ & $10-12$ & $54-56$ \\
\hline
\end{tabular}

Table3: In- Vitro Drug Release Data

\begin{tabular}{|c|c|c|c|c|c|c|}
\hline \multirow{2}{*}{$\begin{array}{l}\text { Time } \\
(\mathrm{min})\end{array}$} & \multicolumn{6}{|c|}{$\%$ CDR } \\
\hline & F1 & F2 & F3 & F4 & F5 & F6 \\
\hline 0 & 0 & 0 & 0 & 0 & 0 & 0 \\
\hline 5 & 35.5 & 38.6 & 41.5 & 54.5 & 39.6 & 48.4 \\
\hline 10 & 56.34 & 59.44 & 59.47 & 74.24 & 58.65 & 59.42 \\
\hline 15 & 60.80 & 64.56 & 76.28 & 83.64 & 71.42 & 76.82 \\
\hline 30 & 73.32 & 72.36 & 83.54 & 86.87 & 75.65 & 80.82 \\
\hline 45 & 85.64 & 86.23 & 92.95 & 91.35 & 81.95 & 83.58 \\
\hline 60 & 89.12 & 90.23 & 96.68 & 92.65 & 88.65 & 90.38 \\
\hline
\end{tabular}

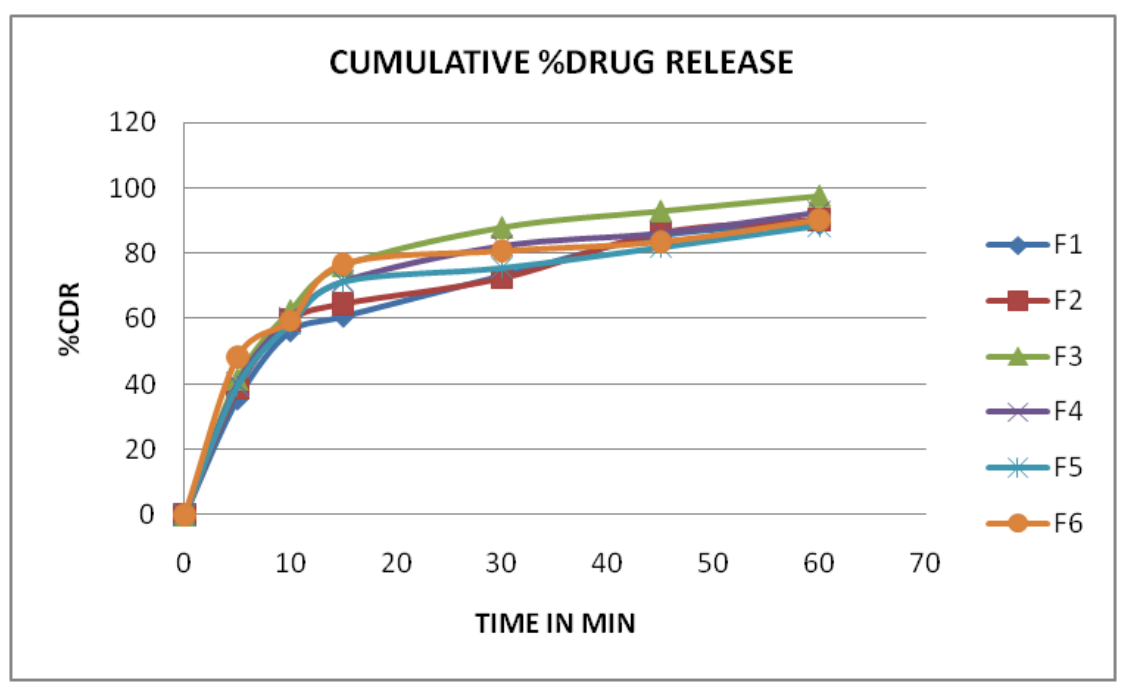




\section{DIS CUSSION}

The weight variation studies for all suppositories were found to be within the acceptable range of $<5$ $\%$.which indicates that calibration of mold was perfect. All the prepared suppositories showed uniformity of drug content was within the permissible range (95 to100 \%) indicating uniformity of drug dispersion in suppositories. The suppositories should have good mechanical strength for handling and transportation. All suppositories were having good mechanical strength in the range of (1.5 to $2.5 \mathrm{~kg} / \mathrm{cm} 2)$ showing optimum hardness. In PEG suppositories increasing the concentration of Peg 4000 and PEG 400 increased the mechanical strength. The macro melting range test was performed for agar based suppositories ranges $\left(54\right.$ to $\left.60^{\circ} \mathrm{C}\right)$. The liquefaction time is the time necessary for suppository to liquefy under pressure similar to those found in the rectum. In agar based suppositories liquefaction temperature and time range $\left(52\right.$ to $\left.58^{\circ} \mathrm{C}\right)$ and time (8 to $\left.12 \mathrm{~min}\right)$. In PEG suppositories ranges liquefaction temperature and time range $\left(46\right.$ to $\left.50^{\circ} \mathrm{C}\right)$ and time (12 to $\left.20 \mathrm{~min}\right)$ as the amount of PEG 4000 and PEG 400 increased. The disintegration test for agar based suppos itories ranges more than $9 \mathrm{~min}$. In PEG suppositories were disintegrated within a time period of (6 to $8 \mathrm{~min}$ ). Suggesting that PEG it was a good disintegrant. In Dissolution study agar, PEG based suppositories indicated that the suppository does not disintegrate, melt or dissolve in the dissolution medium but remain intact. The drug diffuses out from the hydrophilic matrix with time. It was observed that more than $95 \%$ of the drug was released from PEG, agar based formulation (F3).

\section{CONCLUSiON}

It can be concluded that Chlortenoxicam suppositories can be prepared by utilizing both hydrophobic and hydrophilic bases like the PEG and agar base used to formulate conventional rapid release whereas agar based suppositories prepared by addition of HPMC, among all the six formulations $\mathrm{f} 3$ shows better in in disintegration time, liquification time and in dissolution rate.so we conclude that PEG, agar, HPMC shows best combination in preparing of rectal suppositories.

\section{ACKNOWLEDGEMENT}

The authors are Thankful to Rev Dr. K. V. K. Rao and Dr. P. Venkateswara Rao, principal for providing the facilities to carry out this research work in St. Mary's Group of Institutions Guntur.

\section{REFERENCES}

[1] Jain KN et al. Progress in controlled and Novel drug delivery system. CBS Publishers and Distributors, New Delhi. 2004; (1): 96-118.

[2] Boylan CJ.Swarbrick J et al. Encyclopaedia of pharmaceutical technology. 2002; 1 (2): 932-955.

[3] http://en.Wikipedia.org/Wiki/Lornoxicam.

[4] Sweet man SC et al Martindale: The Comp lete Drug Reference. London pharmaceutical press. 2005; 1 (34): 54.

[5] Goodman \& Gilman's by Limbard LB, Hardman $\backslash J G$ et al. The pharmacological basis of therapeutics, International edition. 2001; 1 (10): 687-714.

[6] Swamy PV, Ali M.U, Anandkumar Y et al. Design and evaluation of Rectal Drug Delivery Systems of Non-Steroidal anti-inflammatory drug. International Current Pharmaceutical Journal.

[7] Lachman L. Lieberman AH et al. The Theory and Practice of Industrial Pharmacy CBS Publishers and Distributors. New Delhi. 2009; 564-588.

[8] Carter SJ. Cooper and Gunn's et al. dispensing for pharmaceutical students. CBS Publishers and Distributors. New Delhi. 2000; 1 (12): 232-252.

[9] El-majri M. Sharma RK et al. Formulation and Evaluation of Piro xicam Suppository. International Journal of Drug Delivery. 2010; 1 (2): 108-112.

[10] Saleem MA. Taher M. Sanaullah S. et al. Formulation and evaluation of Tramadol Hydrochloride Rectal Suppositories. International Journal of Pharmaceutical Science. 2008; 2(5): 641-645.

[11] Go wthamarajan K. Venketeshwaran G. Suresh B. et al. Formulation and Evaluation properties of Meloxicam Solid dispersion incorporated Suppositories. Indian Journal of Pharmaceutical Science. 2002; 2(4): 525-528.

[12] Sah LM. Saini RT et al. Formulation development and release studies of indomethacin suppositories. Indian journal of pharmaceutical sciences. 2008; 70(4): 49-501.

[13] Biyani DM. Ranjan P. Chandrashekhar A. at al. Cow Ghee as a Base for Dic lofenac Sodium Suppositories. World Journal of Pharmacy and Pharmaceutical Sciences. 2012; 1(3): 1180-1187. 
[14] De MC. Lefebvre RA. Remon JP et al. Study of the bioavailability of four indomethacin suppository formulation in healthy volunteers. International Journal of Pharmaceutics. 1994; 2(6): 87-91.

[15] Yousif HS et al. Formulation of Tinidazole Rectal Suppositories. Asian Journal of Pharmaceutical Sciences. 2011; 10(2): 69-8

Citation: B.Nagendrababu, et al., "Formulation and Evaluation of Chlortenoxicam Rectal Suppositories", ARC Journal of Pharmaceutical Sciences (AJPS), vol. 4, no. 2, p. 24-28, 2018. http://dx.doi.org/10.20431/2455 $-1538.0402004$

Copyright: (C) 2018 Authors. This is an open-access article distributed under the terms of the Creative Commons Attribution License, which permits unrestricted use, distribution, and reproduction in any medium, provided the original author and source are credited 